\title{
German farmers' intention to use autonomous field robots: a PLS-analysis
}

\author{
Friedrich Rübcke von Veltheim ${ }^{1}$ (D) $\cdot$ Ludwig Theuvsen $^{1} \cdot$ Heinke Heise $^{1}$
}

Accepted: 5 September 2021 / Published online: 25 September 2021

(c) The Author(s) 2021

\begin{abstract}
Autonomous field robots are a promising technology for solving several problems in agriculture, as they are electrical driven, can control weeds single-plant based mechanically or with microdoses of pesticides and exert less ground pressure on the field. Whether such robots will be applied on a large scale in German agriculture depends on various parameters. Therefore, the factors influencing the behavioural intention of farmers with respect to their future adoption of autonomous field robots were investigated. The analysis applies a structural equation model based on an extended version of the Unified Theory of Acceptance and Use of Technology. The dataset, collected in 2019, consists of 500 German farmers. The results reveal significantly positive effects of farmers' expected performance, social influence and trust as well as significantly negative effects of farmers' effort expectancy and anxiety on the behavioural intention to use autonomous field robots. Additionally, moderating effects of age on the relationship of individual constructs to the behavioural intent to use robots could be confirmed. The results provide important information for various stakeholders. Robot suppliers should better inform farmers about the performance of their products, for instance by involving farmers in the development process of the robots. The ecological benefits attributed to field robots could meet public expectations and should be better communicated to address farmers' social influence on the behavioural intention to use the robots. Policymakers could try to create better framework conditions, for example by establishing a stable legal situation for autonomous systems or promote its use.
\end{abstract}

Keywords Autonomous field robots · Farmer · Germany · Partial-least-squares method · Unified theory of acceptance and use of technology model

Friedrich Rübcke von Veltheim

veltheim@uni-goettingen.de

1 Department of Agricultural Economics and Rural Development, University of Göttingen, Platz der Göttinger Sieben 5, 37073 Göttingen, Germany 


\section{Introduction}

In the course of digitalization, various smart farming technologies are currently established in developed countries. In addition to economic benefits such as increased production at lower input costs, they promise a more environmentally friendly farm management (Lutz, 2017). One of the most recent developments in this area are autonomous field robots (AFR). AFR are defined in this paper as robots that act autonomously in a goal-directed manner in an automation-averse environment, i.e., an environment that is not controlled and not fully known, according to automatic interpretations of sensor data from that environment (Hertzberg, 2014). In this context, the focus rests on small-machine AFR concepts. This technology could help to improve the efficiency and sustainability of current plant production by mechanically treating weeds without an operator or chemically treating plant diseases with pesticides in microdoses (King, 2017). This is of particular interest to farmers in Germany because, on the one hand, the range of chemical crop protection agents is becoming ever smaller and, on the other hand, the legal framework for applying pesticides is becoming increasingly restrictive. The elimination of a driver would also increase work safety when handling pesticides by further reducing human contact with these substances. In addition, given the increasing shortage of skilled workers, driverless systems are an advantage for farmers, especially in labor-intensive areas such as the cultivation of specialty crops. Due to the relatively low weight of AFR, soil compaction would substantially be reduced (Minßen et al., 2015). At the same time, small AFR are more scalable than large farm equipment, which could make smallholder farms economically attractive again (King, 2017). Since most AFR concepts are powered by electricity, less noise and pollutants would be emitted as well, which would lead to less annoyance among residents, especially when operating close to residential areas. Kuczera (2006) has demonstrated that farmers are important members in rural communities, and they are influenced by their social environment in their actions. Therefore, they should also be interested in reducing social tensions regarding agriculture.

Nevertheless, various scientists have suggested possible cognitive barriers with the introduction of AFR which could lead to acceptance problems among farmers. The shift from conventional agricultural machinery to highly autonomous unmanned vehicles presents a new scenario of robots working out of the sight of farmers, which some farmers might be sceptical about (Redhead et al., 2015). Redhead et al. (2015) point out that Australian farmers fear the degree of complexity of AFR, the lack of staff qualified to operate this new technology and limited access to reliable commercial communication and data storage services. In addition, Devitt (2018) revealed cognitive barriers to the acceptance of AFR by farmers. She fears that a lack of confidence in autonomous technology, concerns about losing agricultural skills or the loss of social recognition may have a negative impact on the behavioural intention to use AFR. This in turn is countered by falling labour costs and higher harvest expectations (Rial-Lovera, 2018). Kester et al. (2013) were able to confirm for German farmers that although there is a basic willingness to adopt AFR, a certain scepticism about the safety and reliability of such systems exists.

However, since the step from prototype AFR concepts to market-ready products has recently been done, it has become clear that autonomous technology concepts will find their way into agriculture. Nevertheless, it is still unclear how and to what extent this will happen. While Australia was planning the commercial distribution of AFR in 2020, forecasts for Germany predict a broader commercialization of AFR towards 2030 (Pickel, 2019). Despite such predictions and due to its disruptive potential, a successful introduction 
of AFR into agriculture requires its acceptance by society, but also by individual stakeholders, such as farmers or agricultural machinery manufacturers (Brauer, 2017; Redhead et al., 2015; Venkatesh et al., 2003). Following Weidner et al. (2015), among various other parameters, such as the economic feasibility of AFR (i.e., Lowenberg-DeBoer et al., 2020; Shockley et al., 2019), national policies and the legal situation (Basu et al., 2020) for autonomous systems resulting from these policies, an understanding of the various factors determining farmers' acceptance of AFR is needed to provide further information about a potential success of this new technology. This is all the more true as farmers tend to follow the principle of bounded rationality (Simon, 1956) in their decision-making behaviour in contrast to the consistently rational "homo economicus" (Mußhoff et al., 2009). Since AFR have not yet been commercialised on a large scale, there will hardly be any experience of using AFR among farmers (Rübcke von Veltheim et al., 2019). According to Venkatesh et al. (2003) the use behaviour of a new technology is determined by the behavioural intention, which in turn is influenced by various factors (see "Theoretical framework" section). The link between behavioural intention and subsequent adoption has been partially supported by studies of technologies that are part way through the adoption process (e.g., Amin \& Li, 2014; Far and Razaei-Moghaddam, 2015; Schukat et al., 2019; Ambong \& Paulino, 2020). To this end, data were usually collected from different farmers (Ambong \& Paulino, 2020; Schukat et al., 2019) or agricultural experts (Far and Rezaei-Moghaddam, 2015) via surveys or focus group discussions (Amin \& Li, 2014) and analysed using partial least squares (PLS) models. A PLS model combines path analysis, principal component analysis and regression. In detail, it investigates how far the latent variables can be described by indicators or manifest variables (Hornburg \& Giering, 1996). In the absence of studies, yet there is no empirical evidence of the factors driving or prohibiting the intention to use AFR (Redhead et al., 2015; Rial-Lovera, 2018). Thus, the results of this study can contribute to the discussion on autonomous solutions in agriculture and serve as decision support for various stakeholder groups such as agricultural technology manufacturers, policymakers, technology acceptance researchers and farmers.

Therefore, the aim of this study is a first quantification of the determinants influencing the behavioural intention to use AFR. For this purpose, a research model is developed based on the Unified Theory of Acceptance and Use of Technology (UTAUT) according to Venkatesh et al. (2003) and taking into account the findings of Devitt (2018), which will be discussed in more detail in the following. After a description of the methodological approach, the model is applied to an online survey of German farmers $(n=500)$ and finally analysed using a PLS structural equation model. After the presentation of the results, the paper concludes with a discussion of the results and conclusions.

\section{Theoretical framework}

\section{Research model}

For the ex-ante assessment of user acceptance of AFR among farmers, the UTAUT model according to Venkatesh et al. (2003) was chosen from the many existing acceptance models. The UTAUT model is a combination of previous findings from welldocumented acceptance research models and was specifically designed to predict technology acceptance (Venkatesh et al., 2003). It is thus more specific and clarifies more variance in technology acceptance than many of the initial models, such as the theory 
of planned behaviour (TPB) or the technology acceptance model (TAM) (Ajzen, 1991, 2005; Davis, 1989; Venkatesh et al., 2003). In addition, UTAUT is characterized by its generalizability to different forms of new technology and its transferability to different situations (Brauer, 2017). Consequently, it has also been successfully applied in various studies addressing issues in the agricultural context (e.g. for smart farming technologies: Chikoye et al., 2018). The UTAUT also formed the basis for acceptance studies for autonomous robots in the non-agricultural sector, e.g. in the context of care robots (Turja et al., 2019). Thus, a transfer to the analysis of the use of AFR in agriculture seems justified.

According to the UTAUT model, the use behaviour, which indicates the actual use of a new technology, in this case the use of AFR, is determined by the two variables behavioural intention and facilitating conditions. Both behavioural intention and use behaviour, which are described in more detail below, are dependent variables in this model. Since AFR have not widely been introduced into the market, it does not seem to be reasonable to investigate the actual use behaviour of farmers. Hence, this investigation is focused on behavioural intention, which is determined by the independent key constructs: performance expectancy, effort expectancy and social influence. In addition, the variables gender, age, experience, and voluntariness can have a moderating effect on the relationships between these constructs and the behavioural intention, whereby, according to Venkatesh et al. (2003), voluntariness is not seen as a requirement for acceptance research. Furthermore, age and experience can also have moderating effects on the relationship between the construct facilitating conditions and use behaviour (Venkatesh et al., 2003).

In order to adapt the UTAUT model to the context of AFR in agriculture and due to the results of previous studies, the independent variables trust, anxiety and technology commitment (subdivided into the three facets technological interest, technological competence beliefs and technological control beliefs) were added to the key constructs (D'Antoni et al., 2012; Devitt, 2018; Heerink et al., 2010; Kulviwat et al., 2007; Kutter et al., 2011; McAllister, 1995; Neyer et al., 2012; Venkatesh et al., 2011) (see Table 3 in the appendix). The added construct technology commitment complements the UTAUT model with a satisfactorily validated psychometric construct that takes up the use of new technology in general (Neyer et al., 2012). Technology commitment is composed of the three facets, i.e. technological interest, technological competence beliefs and technological control beliefs. The variables trust and anxiety were included based on their empirically proven influence on the intention to use a new technology (Heerink et al., 2010; Kulviwat et al., 2007; Venkatesh et al., 2011). Trust is a major condition for the success of products (MacMillan et al., 2005). It influences the way people interact with other people and whether they are willing to delegate tasks to another agent-no matter if the agent is human or artificial. In this study, trust describes the belief in AFR's performance with personal integrity and reliability (Heerink et al., 2010), because it leads to appropriate reliance on the technology enhancing safety and performance issues, while a lack of trust in new technologies can pose a cognitive acceptance barrier (Devitt, 2018). According to Brehm (1966), anxiety can be seen as the counterpart to trust and, in comparison, has a negative connotation. Heerink et al. (2010) defines anxiety as: "evoking anxious or emotional reactions when it comes to using the system" and assumes an influence in the UTAUT model based on Nomura et al. (2006). Since farmers are free to decide on the use of AFR and are not subject to any constraints and according to Venkatesh et al. (2012), who did the same in an extension (UTAUT 2) of the UTAUT model, the moderator voluntariness was not included in the research model of this paper. Finally, since the commercialization of AFR on large scale has not yet started (Rübcke von Veltheim et al., 2019), the original construct use 
behaviour, which describes the actual usage of AFR, as well as its corresponding construct facilitating conditions were excluded.

The following Fig. 1 summarizes all hypotheses of this study. The three constructs, which were added in order to adapt the UTAUT model to this study, are highlighted in bold letters.

\section{Hypotheses}

The behavioural intention indicates the requests and efforts of a person to perform behaviour to use a new technology. In this study, behavioural intention measures the attitude of potential users towards AFR usage, whereby it was assumed that the relation between the independent variables and the behavioural intention is moderated by gender, age, and work experience. The determinants are explained below and hypotheses formulated.

Performance expectancy refers to the assessment by a potential user of the extent to which the use of a new technology improves the performance of the work within a certain context, in this case arable farming. In many technology acceptance studies, performance expectancy has the strongest influence on the behavioural intention and its relation is often moderated by gender and age (Morris \& Venkatesh, 2000; Venkatesh \& Morris, 2000; Venkatesh et al., 2003). Economic performance plays an important role in investment decisions, e.g. adopting AFR (Shockley et al., 2019). Venkatesh et al. (2003) assume that given the fact with men being highly task-oriented (Minton \& Schneider, 1980), performance expectations that focus on the fulfilment of tasks are also likely to be particularly evident for men. With regard to man-dominated agriculture (Eurostat,

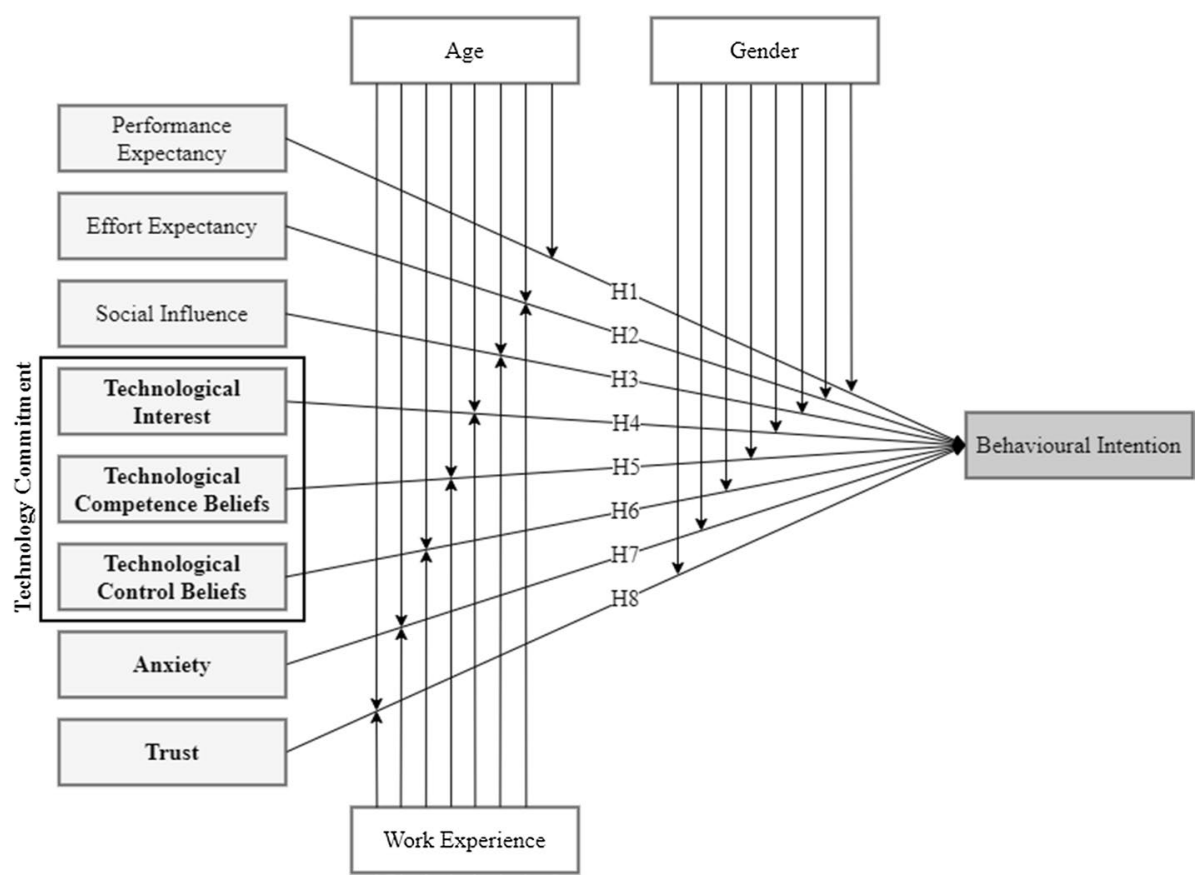

Fig. 1 Research model, adapted from Venkatesh et al. (2003); bold letters = added variables 
2019), an influence of the gender might be demonstrated. Therefore it was assumed that gender has a moderating effect on the relationships between the key constructs (performance expectancy, effort expectancy, social influence, technology commitment, anxiety, and trust) and the behavioural intention. Tamirat et al. (2017) showed for agriculture that younger farmers are more willing to use precision agricultural technologies, such as AFR, based on increased interest in new technologies. In addition, work experience could also have a moderating effect on the relationship between the key constructs and behavioural intention, as experienced farmers may have different views than inexperienced potential users (Levy, 1988). For this reason, the following hypotheses were derived:

H1 Performance expectancy has an influence on the behavioural intention to use AFR.

H1a The effect of performance expectancy on behavioural intention is moderated by age and gender.

Effort expectancy is the degree to which a user believes that a system will be free of effort or difficult to operate. It covers not only financial but also time aspects and is often perceived as higher in a new system at an early stage of implementation. It is predicted to be more challenging for older women with less work experience than for men (Bem \& Allen, 1974; Bozionelos, 1996; Venkatesh \& Morris, 2000). Plude and Hoyer (1985) demonstrated that with increasing age the processing of complex information that may be necessary for the operation of AFR becomes more difficult. The more experienced a user is in handling technology the less effort is expected from a new technology (Levy, 1988). For these reasons, gender, age, and work experience were expected to have a moderating effect on the relationship between the perceived ease of use and the behavioural intention regarding AFR (Gloy \& Akridge, 2000; Hoag et al., 1999; Venkatesh et al., 2003). The following hypotheses were derived:

H2 Effort expectancy has an influence on the behavioural intention to use AFR.

$\mathrm{H} 2 \mathrm{a}$ The effect of effort expectancy on behavioural intention is moderated by age, gender, and work experience.

The social influence refers to the perception of whether people relevant to the potential user believe that the potential user should use the new technology, in this case AFR. This effect also decreases with greater experience (Venkatesh \& Davis, 2000). Regarding agriculture, Kuczera (2006) identified that colleagues, friends, and family members have a social influence on strategic farm decisions. Furthermore, it was observed that farmers' neighbours' experience with new technologies has a significant effect on future use (Foster \& Rosenzweig, 1995). Gender, age, and experience were identified as moderating variables. On the one hand, the literature points out that women react more sensitively to the opinions of others and thus their intention to use AFR is easier to influence (Venkatesh et al., 2003). On the other hand, Rhodes (1983) described an increased need for belonging among older people, so that increased social influence was assumed. Both described influences decrease with increasing experience with technology (Venkatesh \& Morris, 2000).

H3 Social influence affects the behavioural intention to use AFR. 
H3a The effect of social influence on behavioural intention is moderated by age, gender, and work experience.

Technology commitment complements the UTAUT model with a psychometric construct that reflects the use of new technology in general (Neyer et al., 2012). Various studies have shown that younger farmers in particular are more committed to precision agricultural technologies than older ones (D’Antoni et al., 2012; Kutter et al., 2011). In addition, studies on gender differences revealed that young men are more interested in and ready for new technology than women (Venkatesh et al., 2003). It was assumed that this applies also to the relation between technology commitment and the behavioural intention to use AFR. The technology commitment is composed of the three facets technological interest, technological competence beliefs and technological control beliefs.

Following Davis (1989), Neyer et al. (2012) define technological interest as a representative attribute that reflects the subjective evaluation of technological progress. It is well documented that farmers use new production methods when they have a high technological interest (Austin et al., 1998). This is all the more relevant when they are going to pioneer a new technology (Voss et al., 2008). It was therefore be assumed that a potential user with a high technological interest is much more willing to use AFR than a potential user with a more technological aversion.

H4 Technological interest has an influence on the behavioural intention to use AFR.

H4a The effect of technological interest on behavioural intention is moderated by age, gender, and work experience.

Technological competence beliefs is defined by Neyer et al. (2012) based on the concept of competence beliefs by Krampen (1991) as the subjective expectation of opportunities in technology relevant situations. It also reflects the expected adaptability to still unknown technological innovations. Since AFR has not yet been widely commercialized, most potential users may not have gained experience with this new technology. Therefore, it was assumed that technological competence beliefs have an influence on the behavioural intention.

H5 Technological competence beliefs have an influence on the behavioural intention to use AFR.

H5a The effect of technological competence beliefs on behavioural intention is moderated by age, gender, and work experience.

Technological control beliefs, as the final of the three facets of technology commitment, were also defined in reference to Krampen (1991) as individual contingency expectations, which represent the subjective expectation of the results of actions relevant to technology (Beier, 1999). They reflect the level of perceived controllability of technology. Following Devitt (2018), potential AFR users in the initial stage of adoption are often willing to put in a lot of energy to try and make the new technology work. At this stage, a poor user interface design that makes set up laborious, complex or confusing is one of the greatest barriers to the adoption of AFR. In addition, smart farming technologies, such as AFR, are characterized by a large amount of collected data that is 
often beyond the control of potential users, which could have an influence on the behavioural intention.

H6 Technological control beliefs have an influence on the behavioural intention to use AFR.

H6a The effect of technological control beliefs on behavioural intention is moderated by age, gender, and work experience.

Where new technologies such as AFR are introduced, trust leads to a certain degree of dependency on the technology, which causes safety and performance problems, while a lack of trust in new technologies may act as a cognitive barrier to acceptance (Devitt, 2018). Krampen et al. (1982) stated that women often have more trust than men and that trust decreases with age. In addition, Gallimore et al. (2019) found that women report greater trust and perceived trustworthiness of autonomous robots relative to men. Taken the above together, the following was hypothesized:

H7 Trust has an influence on the behavioural intention to use AFR.

H7a The effect of trust on behavioural intention is moderated by age, gender, and work experience.

In the light of the aforementioned studies by Gallimore et al. (2019) and Krampen et al. (1982) and in addition to the findings of Ghazali et al. (2018), who reported that women evidenced lower anxiety to a male robot relative to a female robot, it was assumed that the construct anxiety also differs in terms of gender and age. Hence, it was hypothesized that it also has an influence on the behavioural intention to use AFR.

H8 Anxiety has an influence on the behavioural intention to use AFR.

H8a The effect of anxiety on behavioural intention is moderated by age, gender, and work experience.

\section{Material and methodology}

\section{Study design and analysis}

In July and August 2019, a standardized online survey of farmers $(n=500)$ was performed in Germany in order to assess farmers' behavioural intention to use AFR as well as its determinants. Personalised links for the online survey were used to ensure that each participant could only answer the questionnaire once. The survey was pre-tested for two weeks and was finally implemented with the help of the Unipark software (Globalpark AG). The attributes of the individual questions and statements were measured using five-point Likert scales (from 1 "fully disagree" to 5 "fully agree"). In order to assure a consistent knowledge base about AFR among the participating farmers, a three-minute, informative video on how AFR work and the possible areas of application was presented in the beginning of the questionnaire. Additionally, control questions were established for quality assurance. 
Furthermore socio-demographic and farm characteristics were inquired. For the recruitment of survey participants, various channels were used, such as the mailing lists of the German Farmers' Association, the publication of the survey link on social media pages of various agricultural journals, an interview with $\mathrm{f} 3$ magazine, and the use of the published mailing lists of farms, certified to train farmers, as well as private contacts. After eliminating incomplete datasets, 533 complete questionnaire replies could be compiled. However, further observations had to be excluded from analysis. The exclusion criteria were unsystematic response behaviour, processing time that deviated significantly from the average $(18 \mathrm{~min})$ and an incorrect answer to the quality control question. After the dataset had been cleared of incorrectly completed forms, 500 observations remained for further investigation.

The data analysis was done based on the extended UTAUT model (see "Theoretical framework" section). All constructs described above, which will be investigated in relation to the behavioural intention to use AFR, are latent variables. Latent variables cannot be observed directly and must therefore be described with the help of empirical indicators (Hornburg \& Giering, 1996). All empirical indicators which were used to describe the latent variables are illustrated in Table 3 in the appendix. To further analyse the relationships of the latent variables, the component based PLS structural equation model (SEM) was used. A PLS SEM consists of two elements: a structural model, which displays the relationships between the constructs, and a measurement model, which displays the relationships between constructs and indicators (Hair et al., 2016). The measurement model can either be formative or reflective (Diamantopoulos, 2011). In this paper a reflective measurement model is used. This was done because the individual indicators of the respective constructs are highly significantly correlated with each other and the exclusion of one indicator does not trigger a sizeable effect on the associated construct (e.g., Hair et al., 2016). The model differentiates between dependent (endogenous) and independent (exogenous) latent variables (Henseler, 2005). PLS is characterized by its suitability for complex models and explorative studies and was therefore chosen for the present analysis.

To test the moderating effects of gender, age and work experience (H1a-H8a), multigroup analysis (MGA) were performed because they allow testing a moderator continuously throughout the research model (Henseler \& Chin, 2010). Further, MGA is very well suited to calculate the strength of the moderating effects (Baron \& Kenny, 1986; Sarstedt et al., 2011). It should be noted that a moderator can change not only the strength but also the direction of a relationship in the research model. Two separate bootstraps are calculated and compared for the MGA (Henseler \& Chin, 2010). The estimated parameters from the bootstrap calculation help to check the probability of differences between groups. If there is a group difference that is significant, a moderating effect can be assumed (Henseler et al., 2009). For age and work experience a median split was performed to divide the moderators into two groups. The younger group included everyone born after 1978; the older group included everyone born before 1979. The less experienced group included those with less than 22 years of work experience; the experienced group included those with more than 21 years of work experience. Gender was divided in male and female. Evaluations were performed with the program SmartPLS v. 3.2.8.

\section{Quality criteria}

The analysis of the PLS model is based on a two-stage approach: First, the quality of the structural model is evaluated with regards to its reliability and validity; second, the 
measurement model is checked. Since the objective of PLS SEM is the maximization of the explained variance for the endogenous latent variables, in this study the behavioural intention to use AFR, the quality evaluation of the measurement model as well as of the structural model concentrate on key figures for the PLS path model's predictive power (Hair et al., 2016). For the reflectively specified measurement model, this includes internal consistency reliability, convergent and discriminant validity. The internal consistency reliability indicates how well the individual indicators explain the underlying construct. It is evaluated using the two criteria composite reliability (CR) and Cronbach's alpha (CRA). The CR should be higher than 0.7 , whereby values above 0.6 are also considered to be acceptable in explorative studies (Hair et al., 2016). The same specifications apply to CRA. CRA tends to overestimate the true value, whereas CRA tends to underestimate it, so the true value may lie between these two criteria (Hair et al., 2016).

To evaluate the convergent validity, which describes the extent to which a measurement is positively correlated with an alternative measurement of the same construct (Hair et al., 2016), the two criteria: indicator reliability and average variance extracted (AVE) were used. Indicator reliability of a construct reveals how much the associated indicators have in common, whereas AVE describes how much of the variance in an indicator is explained by the construct (Hair et al., 2016). For indicator reliability, the loading of an indicator should be above 0.7 , whereas the AVE should be above 0.5 , so that the construct explains at least $50 \%$ of each indicator's variance (Hulland, 1999). The discriminant validity is the extent to which one construct differs from another construct (Hair et al., 2016). Its measurement is thus concerned with the empirical validity of a construct. To determine the discriminant validity, the Fornell-Larcker criterion, cross loadings and the relatively new heterotrait-monotrait ratio (HTMT) were used. The Fornell-Larcker criterion compares the square root of the AVE values with the latent variable correlations and tests whether a construct shares more variance with its associated indicators than with any other construct (Fornell \& Larcker, 1981). To fulfil the criteria, the Fornell-Larcker criterion should be larger than the AVE. To further test if the discriminant validity has been established, an indicator's reliability on the associated construct should be greater than any other of its cross-loadings (Chin, 1998). Otherwise an indicator should be removed (Hair et al., 2016). Following Henseler et al. (2015), the Fornell-Larcker criterion and cross-loadings alone are not sufficient to fulfil the discriminant validity criteria. Therefore, the HTMT is needed, which describes the relationship between indicators that measure different constructs, and between indicators that each measures its own construct (Hair et al., 2016). To have no lack of discriminant validity the HTMT should not exceed 0.85 , nor should the confidence interval contain the value 1 (Henseler et al., 2015). The quality criteria described for the reflective measurement model are summarized in Table 1.

After the measurement model was tested, the results of the structural model were evaluated. This was done in six steps: (1) assess structural model for collinearity, (2) assess the significance and relevance of the structural model relationships, (3) assess the level of $\mathrm{R}^{2}$, (4) assess the $f^{2}$ effect size, (5) assess the predictive relevance $Q^{2}$, and (6) assess the $q^{2}$ effect size (Hair et al., 2016). To test collinearity in the structural model, the variance inflation factor (VIF) was used, which describes the degree to which the standard error has been increased due to the presence of collinearity (Hair et al., 2016). If the VIF is above 5 (80\% of the indicators' variance has been verified by the remaining indicators related with the same construct), a critical level of collinearity is indicated and an elimination of constructs, a predictor merge into a single construct or the creation of higher-order constructs should be considered in order to treat collinearity problems (Hair et al., 2011). The significance and relevance of the structural model relationships was assessed through non-parametric 
Table 1 Quality criteria of reflective measurement models

\begin{tabular}{ll}
\hline Quality criteria & Requirement \\
\hline Internal consistency reliability & $\begin{array}{l}\text { Composite reliability }>0.6 \text { and }<0.9 \\
\text { Cronbach's alpha }>0.6 \text { and }<0.9\end{array}$ \\
Convergent validity & Indicator reliability $>0.7$ \\
& AVE $>0.5$ \\
Discriminant validity & Fornell-Larcker criterion $>$ AVE \\
& Cross loadings $<$ loadings on the \\
& associated constructs \\
& HTMT of the correlations $<0.85 ;$ \\
& confidence interval $\neq 1$
\end{tabular}

Source: Authors' illustration according to Hair et al. (2016)

bootstrapping. The bootstrapping method generates subsamples that are randomly drawn from the data set and after that are used to estimate the PLS path model (Davison \& Hinkley, 1997; Efron \& Tibshirani, 1986). The p-values should be lower than 0.05 (significant), 0.01 (very significant) or 0.001 (highly significant). When determining the $\mathrm{R}^{2}$ value, it applies that the greater the $\mathrm{R}^{2}$, the higher the proportion of the declared variance (Hair et al., 2016). The level of an acceptable $\mathrm{R}^{2}$ value depends on the research discipline. Thus, for some social scientists, a value of $\mathrm{R}^{2}$ greater than 0.25 is acceptable, which ensures that at least $25 \%$ of the variance of the endogenous variable is explained by the influencing factors (Hair et al., 2011; Henseler et al., 2009). The $\mathrm{f}^{2}$ value explains to which extent an exogenous latent variable contributes to the $\mathrm{R}^{2}$ value of an endogenous latent variable, where $\mathrm{f}^{2}$ values of 0.02 point to a small, 0.15 to a medium, and 0.35 to a large effect of an exogenous construct on an endogenous construct (Cohen, 1988). $\mathrm{Q}^{2}$ uses blindfolding procedure to assess the predictive relevance of a model (Götz et al., 2010). The division of the sample size by the omission distance (D) should not give an integer, where $\mathrm{D}$ should be selected between 5 and $10 . \mathrm{Q}^{2}$ values above 0 indicate a predictive relevance of the model to the endogenous construct (Chin, 1998). In the last step the $\mathrm{q}^{2}$ effect size was assessed. It is a criterion for evaluating the relative predictive relevance of an exogenous construct to an endogenous construct and indicates a small (0.02), medium (0.15) or large $(0.35)$ predictive relevance of an exogenous construct for an endogenous construct (Hair et al., 2016).

\section{Results}

\section{Sample description and descriptive results}

The descriptive statistics are shown in Table 2. The sample consists of $91.6 \%$ male and $8.4 \%$ female respondents. This is nearly representative for the gender ratio of farm managers in Germany (90.4\% male; $9.6 \%$ female), as recorded in the last agricultural census in 2016 (Eurostat, 2019). The average age of the respondents is 41.5 years. In terms of age distribution, the sample is not representative for the population of those employed in agriculture in Germany in 2016. For example, farmers under the age of 35 are clearly over-represented and farmers over the age of 44 are clearly under-represented in the sample (German Farmers' Association 2019). Work experience is relatively high, since about $67 \%$ of the respondents have worked in agriculture for more than 10 years. The majority 
Table 2 Sample statistics $(n=500)$

\begin{tabular}{|c|c|c|c|c|}
\hline Variable & Description & Frequency & Percentage (\%) & $\begin{array}{l}\text { German } \\
\text { average } \\
(\%)^{\mathrm{b}}\end{array}$ \\
\hline \multirow[t]{2}{*}{ Gender $^{\mathrm{a}}$} & Male & 458 & 91.6 & 90.4 \\
\hline & Female & 42 & 8.4 & 9.6 \\
\hline \multirow[t]{5}{*}{$\mathrm{Age}^{\mathrm{a}}$} & Under 25 & 52 & 10.4 & 7.7 \\
\hline & $25-34$ & 144 & 28.8 & 14 \\
\hline & $35-44$ & 89 & 17.8 & 16.4 \\
\hline & $45-54$ & 108 & 21.6 & 28.3 \\
\hline & Older than 55 & 107 & 21.7 & 33.6 \\
\hline \multirow[t]{4}{*}{ Work experience $^{\mathrm{a}}$} & Less than 10 years & 165 & 33.0 & n.a \\
\hline & 10 to 20 years & 105 & 21.0 & n.a \\
\hline & 21 to 30 years & 130 & 26.0 & n.a \\
\hline & More than 30 years & 100 & 20.0 & n.a \\
\hline North & $\begin{array}{l}\text { Bremen, Hamburg, Lower Saxony, } \\
\text { Schleswig-Holstein }\end{array}$ & 181 & 36.2 & 18.4 \\
\hline East & $\begin{array}{l}\text { Berlin, Brandenburg, Mecklenburg Western } \\
\text { Pomerania, Saxony, Saxony-Anhalt, } \\
\text { Thuringia }\end{array}$ & 101 & 20.2 & 9.6 \\
\hline West & North Rhine-Westphalia, Hesse & 80 & 16.0 & 18.0 \\
\hline South-West & $\begin{array}{l}\text { Baden-Württemberg, Rhineland-Palatinate, } \\
\text { Saarland }\end{array}$ & 89 & 17.8 & 21.6 \\
\hline South-East & Bavaria & 49 & 9.8 & 32.5 \\
\hline \multirow[t]{2}{*}{ Farm management } & Conventional & 429 & 85.8 & 88.0 \\
\hline & Organic & 71 & 14.2 & 12.0 \\
\hline \multirow[t]{9}{*}{ Farm size } & Less than 5 hectares & 4 & 0.8 & 0.2 \\
\hline & 5 to 9 hectares & 7 & 1.4 & 2.0 \\
\hline & 10 to 19 hectares & 18 & 3.6 & 4.8 \\
\hline & 20 to 49 hectares & 52 & 10.4 & 12.5 \\
\hline & 50 to 99 hectares & 99 & 19.8 & 19.2 \\
\hline & 100 to 199 hectares & 110 & 22.0 & 20.5 \\
\hline & 200 to 499 hectares & 102 & 20.4 & 16.0 \\
\hline & 500 to 1000 hectares & 51 & 10.2 & 10.1 \\
\hline & More than 1000 hectares & 57 & 11.4 & 14.7 \\
\hline
\end{tabular}

${ }^{\mathrm{a}}$ Gender, age and work experience classes were used as moderators in the UTAUT model

${ }^{\text {b}}$ Destatis (2019), German Farmers' Association (2019) Source: Authors' calculations and illustration

of the farmers surveyed work in the regions North (Bremen, Hamburg, Lower Saxony, and Schleswig-Holstein: about 36\%), East (Berlin, Brandenburg, Mecklenburg Western Pomerania, Saxony, Saxony-Anhalt, and Thuringia: about 20\%) and South-West (BadenWürttemberg, Rhineland Palatinate, and Saarland: about 18\%). With the exception of the South-West region (around 22\% national average) this does not match the national distribution of the farms in 2019. On a national average most farms are located in the SouthEast region (Bavaria: around 32\%) (Destatis, 2019). With respect to farm management practices, the sample represents approximately the national average for 2018 , as $14.2 \%$ 
(national average: 12\%) of the respondents farm organically and $85.8 \%$ (national average: $88 \%$ ) conventionally (German Farmers' Association 2019). In 2019, there were about 266,600 farms in Germany cultivating 16.7 million hectares of agricultural land, including 11.7 million hectares of arable land (Destatis, 2019). The farm size structure of the sample is shifted towards larger farms in comparison to the national average.

In general, the respondents seem to be positive about the use of AFR in agriculture (see Table 3 in the appendix). The performance expectancy scored the highest mean agreement $(\mu=4.07)$, followed by behavioural intention $(\mu=3.80)$, social influence $(\mu=3.32)$, trust $(\mu=3.27)$ and technology commitment $(\mu=3.20)$. Effort expectancy $(\mu=2.43)$ and anxiety $(\mu=1.79)$ received the lowest agreement. Within the construct perceived usefulness, the greatest benefit $(\mu=4.49 ; \sigma=0.729)$ was seen in the expected reduction of workload and the least benefit $(\mu=3.87 ; \sigma=0.945)$ in the more environmentally friendly management through the use of AFR. In terms of expected effort, the least difficulties $(\mu=2.87$; $\sigma=0.962$ ) are associated with the safe handling of AFR, whereas slightly more problems are seen in the operation $(\mu=2.14 ; \sigma=0.850)$. Overall, on average more benefits $(\mu=4.07$; $\sigma=0.690)$ than efforts $(\mu=2.43 ; \sigma=0.710)$ are expected. With regard to the social influence, marginally more weight is given to the good impression on society through the use of AFR $(\mu=3.47 ; \sigma=0.938)$ than to the impression on other farmers $(\mu=3.25 ; \sigma=0.938)$. The judgement of the farmers surveyed turned out to be clearer in the case of technology commitment. Here, the highest agreement is with the statement of being curious about new technologies $(\mu=4.42 ; \sigma=0.732)$, while farmers are least afraid of damaging these new technologies when using them $(\mu=1.58 ; \sigma=0.735)$. Trust in AFR is slightly higher in terms of them making the right decisions $(\mu=3.40 ; \sigma=0.910)$ compared to following up on these decisions $(\mu=3.16 ; \sigma=0.891)$. In contrast, there is slightly more concern about using AFR incorrectly $(\mu=2.24 ; \sigma=0.971)$, while almost none of the farmers surveyed find AFR intimidating $(\mu=1.43 ; \sigma=0.708)$.

The positive general orientation is also reflected in the dependent variable (behavioural intention) of the research model $(\mu=3.80)$. A more detailed understanding of the distribution across the individual indicators of behavioural intention is provided in Fig. 2. Most of the farmers interviewed were interested in becoming familiar with the new technology during the first days of AFR use on their farm $(\mu=4.53)$ and learning how to use it properly $(\mu=4.60)$. However, farmers were rather indifferent to the implementation of AFR on their farms $(\mu=3.44)$, and there were no plans yet to use AFR in the nearest future $(\mu=2.70)$. The standard deviations range from $\sigma=0.722$ to $\sigma=1.163$.

\section{Evaluation of quality criteria of the model}

A PLS was used to analyse the extended UTAUT model and the derived hypotheses. First, the measurement model was evaluated by the quality criteria regarding reliability and validity as described in the "Material and methodology" section. The internal consistency reliability of each construct was assessed by CRA and the CR. Table 3 (see appendix) shows that all CRA (ranging from 0.653 to 0.787 ) and CR (ranging from 0.783 to 0.858 ) values are above 0.6 and can therefore be considered acceptable for this explorative study. The convergent validity was computed using the indicator loadings and the AVE. To test the significance of the indicator loadings the bootstrap procedure was used with 5000 subsamples. Most of the indicator loadings are above 0.7 (ranging from 0.657 to 0.910 ). Those indicators with a loading between 0.657 and 0.708 remained in the model, since its removal did not increase the CR of the corresponding construct. All AVE values exceeded 


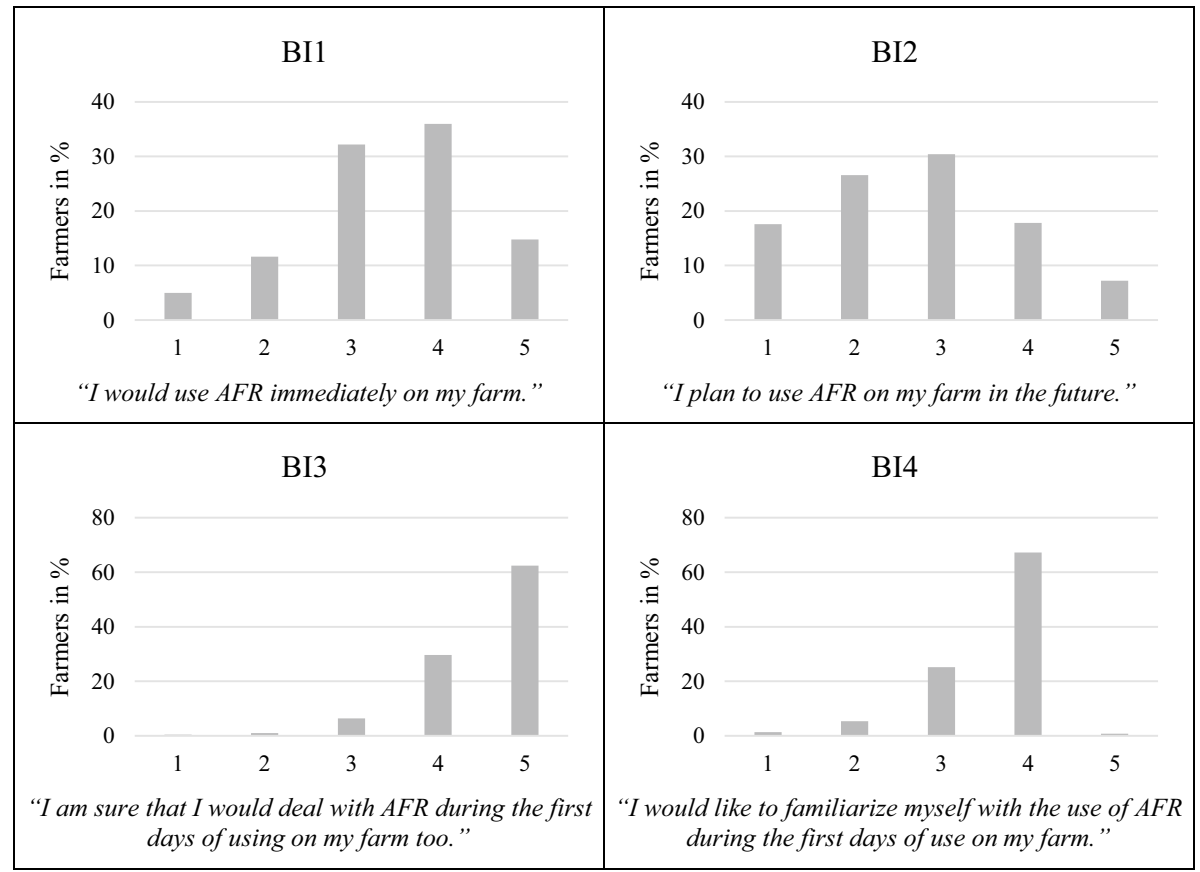

Fig. 2 Response distribution in the construct behavioural intention. Scale form $1=$ totally disagree to $5=$ totally agree; $n=500$

the threshold of 0.5 (ranging from 0.533 to 0.749 ). To determine the discriminant validity, the Fornell-Larcker criterion, cross loadings and the relatively HTMT were checked. None of the observed AVE was higher than the squared correlations, so the Fornell-Larcker criterion was fulfilled (see Tables 3 and 4 in the appendix). All indicators' cross loadings had a significantly higher loading on its own construct than on others, therefore no indicators had to be removed. The HTMT did not exceed 0.85 , nor did the confidence interval contain the value 1 , so that the discriminant validity can be assumed to be acceptable.

\section{Hypothesis verification}

The results of the PLS analysis with standardized path coefficients are shown in Fig. 3. Six out of nine hypotheses derived from the extended UTAUT model could be supported (H1, H2, H3, H4, H7, and H8). Performance expectancy $(0.314, \mathrm{p} \leq 0.001)$, social influence $(0.214, \mathrm{p} \leq 0.001)$, technological interest $(0.124, \mathrm{p} \leq 0.01)$ and trust $(0.132, \mathrm{p} \leq 0.001)$ had significantly positive effects on the behavioural intention to use AFR. A significantly negative influence on the behavioural intention to use AFR for effort expectancy $(-0.135$, $\mathrm{p} \leq 0.001)$ and anxiety $(-0.124, \mathrm{p} \leq 0.01)$ was observed. The effects of performance expectancy and social influence were the strongest. The research model accounted for $51.6 \%$ $\left(\mathrm{R}^{2}\right)$ of the variance in behavioural intention. For the gender and work experience, no moderating effect could be identified, whereas age was confirmed as a moderator. Regarding age, the moderating effect was confirmed for the two facets technological interest and technological competence beliefs of the technology commitment construct (see Table 6 in 


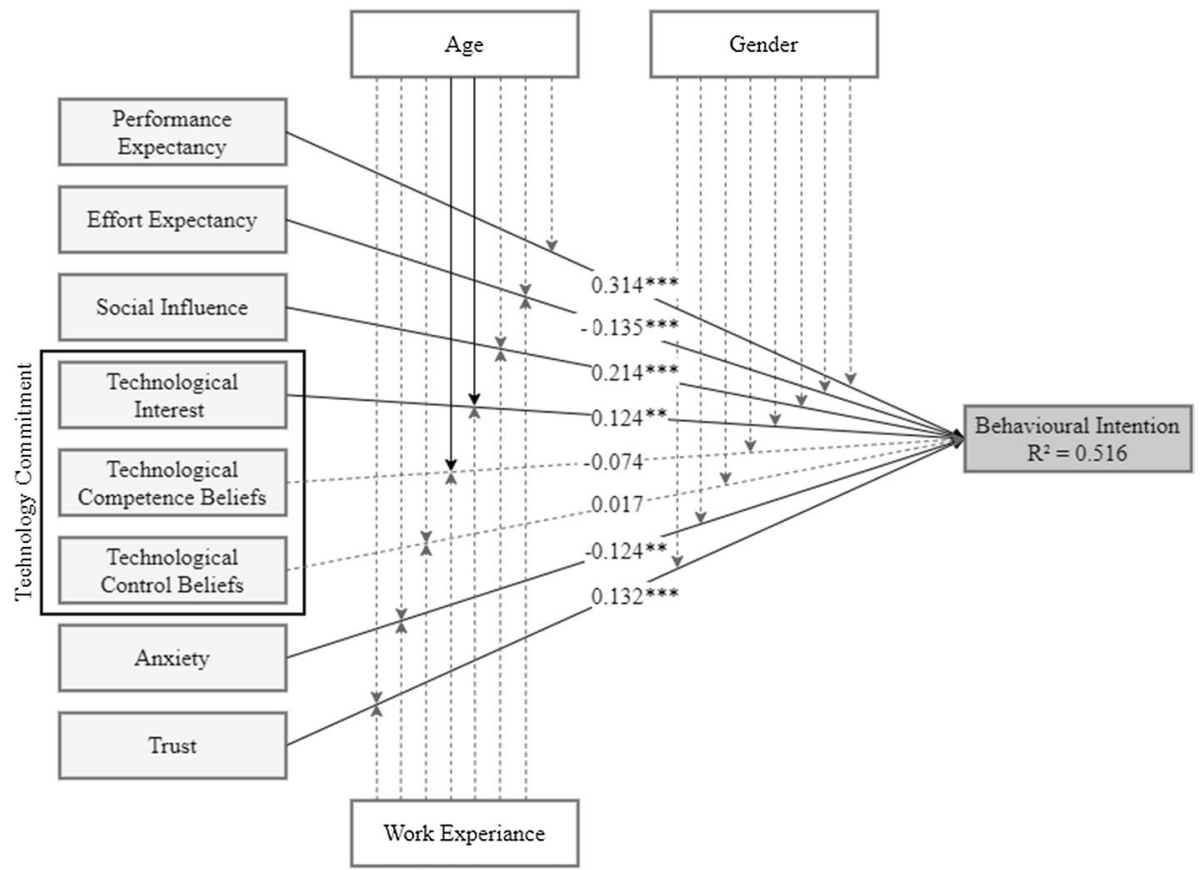

Fig. 3 Results of the PLS analysis. Significance level: *p $\leq 0.05, * * \mathrm{p} \leq 0.01$, *** $\leq 0.001$; broken line: not significant

the appendix). In detail, there was almost no influence (0.016) of technological interest on behavioural intention for the younger group, whereas the older group showed a higher path coefficient (0.220). The opposite was observed for the technological competence beliefs. In this case the influence was negative and significantly higher in the younger group $(-0.178)$ than in the older group (0.013). According to Chin (1998), path coefficients below 0.1 are not interesting to interpret although it is significant. As a result, the moderator hypotheses 1a, 2a, 3a, 6a, 7a, and 8a were not supported, whereas hypotheses $4 \mathrm{a}$ and $5 \mathrm{a}$ were partly supported.

\section{Discussion}

After analysing the descriptive results (see Table 3 in the appendix) of the survey $(n=500)$ based on the extended UTAUT model, it was found that the respondents are positive about AFR, although the use of AFR on their own farms is not currently planned by the respondents. This was reflected in specific by performance expectancy and the resulting intention of farmers to use AFR. It is hoped that a high degree of technology autonomy will reduce farmers' workload, which is in line with the results of Rial-Lovera (2018), who analysed drivers, barriers and opportunities for adoption of agricultural robotics in California (USA) by applying qualitative expert interviews. The positive behavioural intention underlines the respondents' willingness to use AFR. This is confirmed by the indefiniteness regarding effort expectancy, the lack of anxiety regarding AFR and the respondents' high technology 
commitment. Especially the latter is important for the future adoption of AFR. For example, Austin et al. (1998) have already shown that farmers are more likely to use new production methods if they have a high level of technological interest; even more so if they want to adopt a technology as a pioneer (Voss et al., 2008).

Furthermore, the PLS analysis showed that the six constructs performance expectancy, effort expectancy, social influence, technological interest, anxiety and trust significantly determine farmers' behavioural intention to use AFR and that the assumed research model has a relatively high explanatory power $\left(\mathrm{R}^{2}=51.6 \%\right)$. The fact that the strongest significant positive influence on behavioural intention derives from performance expectancy has been demonstrated in many other studies on technology acceptance (Venkatesh et al., 2003). The significant influence of performance expectancy can also be explained by the relative importance of the economic benefits expected from the use of AFR (Redhead et al., 2015). For example, Shockley et al. (2019) confirmed in their comparison of conventional and autonomous machinery for grain crop production under various scenarios that AFR will never be adopted, if they are not profitable for producers. In their case study, autonomous machinery was more profitable than conventional machinery for all scenarios. In addition, all studies published after 1990 on the economics of AFR that were reviewed by Lowenberg-DeBoer et al. (2020) figured scenarios in which autonomous robotic technologies are profitable. At the same time, they identified a need for in-depth research on economic implications due to the different study designs, assumptions and calculations only based on data from prototypes.

The significant positive effect of social influence on the behavioural intention to use AFR may result from the fact that farmers are important members of rural communities (Retter et al., 2002). Therefore, the expectations of third parties are crucial in their decision-making process (Solano et al., 2003; Zimmermann, 2003). This supports the concerns expressed by Devitt (2018) that farmers could fear a social cognition loss due to AFR's on-farm implementation, which, if so, could lead to AFR possibly not reaching the postadoption phase of acceptance and use. Various studies have shown that farmers perceive society's increasingly negative perception of their production methods as a burden (Zander et al., 2013). In contrast to this a consumer survey carried out in EU Member States in 2012 found that only $6 \%$ of respondents would agree to a ban on robots in agriculture (Eurobarometer, 2012). If AFR lead to wider consumer acceptance than current agricultural production methods, this could be an additional incentive for farmers to use AFR.

Regarding technology commitment, only the facet technological interest had a significant influence on the behavioural intention to use AFR. The intention to use new technologies often requires a certain affinity for or interest in technology (Austin et al., 1998; Voss et al., 2008). For the behavioural intention to use a new technology, trust is one of the most important predictors (Gefen et al., 2003). The knowledge about the reliability of a system determines how to use it (Dixon \& Wickens, 2006; Dixon et al., 2007; Meyer, 2001, 2004). Since trust had a positive influence on the behavioural intention, it can be said that safety and performance issues are important in relation to AFR. Nevertheless, it must be assumed that most farmers are unlikely to be aware of the detailed requirements that their farm must meet in order to fulfil AFR's needs or whether the technology works reliably and is therefore trustworthy (Redhead et al., 2015). Similarly, the conclusion reached by Devitt (2018) that a lack of trust could have an inhibiting effect on the behavioural intention to use AFR could be confirmed indirectly. 
The significant negative influence of effort expectance on the intention to use AFR was to be expected, since decision-making in agriculture traditionally tends to avoid risk rather than increase efficiency (Tey \& Brindal, 2012). According to Redhead et al. (2015), Australian farmers fear the level of complexity of AFR, the lack of employees skilled in operation of this new technology and limited access to reliable economical communication and data storage service. This could also be an issue for German farmers, as they work in a developed country as well. At the same time, anxiety, as the counterpart of trust, could also be validated by its significantly negative influence on the behavioural intention to use AFR, although the positive effect of trust was greater than the negative effect of anxiety (Heerink et al., 2010).

The moderating influence of age was demonstrated for the relation between the behavioural intention and the two facets technological interest and technological competence beliefs of the technology commitment construct. Younger farmers showed a higher level of technological interest and believe that they have more skills in handling new technology than older farmers. These results are in line with many other studies analysing the effect of age and technological interest on new technologies in agriculture (Isgin et al., 2008; Pierpaoli et al., 2013; Tey \& Brindal, 2012), as younger farmers are more likely to adopt new agricultural technologies (Larson et al., 2008).

Work experience in no case moderates the relationships between the independent and dependent variables in the extended UTAUT model. However, former studies showed that experience plays an important role for the acceptance of new technologies or systems in agriculture (Hiebert, 1974; Schukat et al., 2019). It remains to be considered whether a median split regarding MGA draws a suitable dividing line for age and work experience, since, for example, farmers with more than 10 years of work experience could also be considered as experienced.

However, this study finds its limitations in several biases which cannot be excluded due to the way the data is collected. Particularly when it comes to the self-assessment of respondents with regard to certain beliefs, phenomena such as response behaviour not corresponding to reality as a result of social desirability, a tendency towards the middle (Bortz \& Döring, 2006) or simple incomprehensibility of the question asked can always occur. In addition, online surveys often tend towards self-selection instead of the desired random selection (Jacobs et al., 2009). Thus, opponents or supporters of AFR may feel addressed by the questionnaire and take up a disproportionate share of the sample. Similarly, both age and farm size structure of the investigated sample is younger and larger than German average, so that the result may indicate a more technophile attitude of respondents compared to the German average. Nevertheless, since AFR will only be relevant for future operational decisions, a younger sample composition can be assumed to be more relevant. For the MGA, the sample is divided into two groups, which leads to a high degree of data aggregation and a loss of information (Orcutt et al., 1968). Thus, if the moderating effects are examined differently, they could possibly be stronger or weaker.

Regarding the path coefficients, it is questionable whether values smaller than 0.1 should be considered for interpretation. Reference values for path coefficients differ in the reviewed literature. Some consider a value smaller than 0.2 to be negligible (Chin, 1998), while others consider only path values smaller than 0.1 to be negligible (Lohmöller, 1988). The path coefficients of technological interest $(0.124)$ and anxiety $(-0.124)$ were only 
slightly above an absolute value of 0.1 and therefore had only a small influence but were nonetheless considered in the discussion. Since AFR is a future technology in Germany, it was only possible to determine the behavioural intention to use AFR. But a gap is often observed between the intention to use and the actual usage behaviour (Renner et al., 2007), so that farmers may behave differently than ex-ante intended. The results should therefore be considered cautiously. However, despite the limitations mentioned, the model can explain more than $50 \%$ of the variance. Therefore, it seems suitable to predict the behavioural intention of farmers towards AFR.

It is worth noting that the added constructs trust and anxiety had significant effects on the behavioural intention to use AFR. Thus, the study could again prove the adaptability of the UTAUT and furthermore its transferability to the context of autonomous agritechnical concepts, which is of interest for future technology acceptance studies using the UTAUT model.

The findings provide several implications for agricultural manufacturers and politicians. The present results show a broadly positive position within the agricultural sector in favour of this new technology, although this should be viewed with some caution as the study is not entirely representative in its composition. The absence of anxiety in relation to AFR and the high level of technological commitment are further evidence for this. Austin et al. (1998) have already shown that farmers are more likely to use new production methods if they have a high level of technological interest; even more if they want to adopt a new technology as a pioneer (Voss et al., 2008). Manufacturers should build on this and continue to increase the performance expectations of farmers, for example by demonstrating the economic attractiveness of AFR compared with conventional agricultural machinery in certain fields. In case of Australia farmers welcomed the opportunity to be involved in the prototype development of AFR, which could also be an option for Germany (Redhead et al., 2015). The ecological benefits attributed to AFR could meet public expectations of farming and should be better communicated to address the social influence on the behavioural intention to use AFR (Friedrich et al., 2012). In addition to better communication of the benefits, specific incentives, such as training on AFR, could be provided to reduce effort expectations and anxiety. Devitt (2018) sees this as one of the greatest barriers to the adoption of AFR. There are various ways in which policymakers can promote the use of AFR or reduce the risks involved (Gerybadze, 2015). For example, a supply-side promotion in sense of a technology push or a demand-side promotion in sense of a market pull would be possible. In addition, politicians could try to create better framework conditions, for example by establishing a stable legal situation or financial support programmes for autonomous systems. Another approach could target society or the social environment of farmers, for example by proactively providing information or education. 


\section{Conclusions}

AFR are considered to be a promising technology for addressing many agricultural production challenges as well as a growing conflict in Western Europe between societal expectations regarding ecological sustainability and modern farming practices (Minßen et al., 2015). However, this promising technology will only be established on a broad basis if it is accepted by its potential future users (Redhead et al., 2015; Venkatesh et al., 2003). The technology acceptance is determined by various parameters, such as the economic feasibility of the technology, national policies and the legal situation resulting from these policies. For a new technology, like AFR, the acceptance among farmers is expressed essentially by the behavioural intention to use the technology, which has been partially supported by studies of technologies that are part way through the adoption process (e.g., Amin \& Li, 2014; Far and Razaei-Moghaddam, 2015; Schukat et al., 2019; Ambong \& Paulino, 2020). Therefore, the aim of this study was a first ex-ante quantification of the determinants influencing the behavioural intention of farmers to use AFR. For this purpose, a research model was developed based on the UTAUT proposed by Venkatesh et al. (2003).

The results offer a range of opportunities for further studies. For example, the results found must be confirmed or rejected by a representative sample. In addition, discrete choice experiments could be used to aggregate the collected preferences into more robust results. Finally, comparative follow-up studies should survey the actual adoption behaviour of farmers as soon as AFR have been introduced to the market on a broader scale and initial experience with this new technology is available. Although a fundamentally positive view of farmers in Germany towards AFR could be demonstrated, a differentiated opinion of other stakeholder groups, such as the established agricultural machinery manufacturers or AgTech startups, has not yet been researched in Germany. Due to the high level of public interest in agricultural production methods (Zander et al., 2013; Zühlsdorf et al., 2016), it would also be interesting to survey public attitudes towards AFR. If there is too much resentment against AFR, this could hinder the introduction of this new technology (Ferretti \& Pavone, 2009).

\section{Appendix}

See Tables 3, 4, 5, 6, 7 


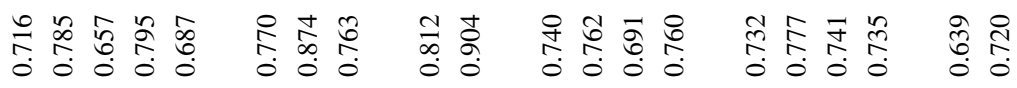

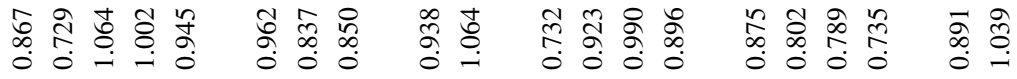

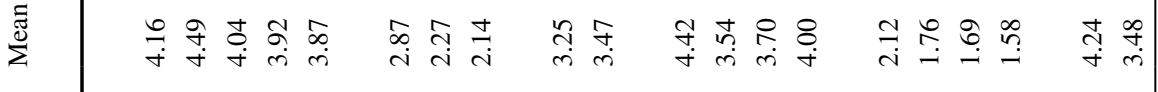

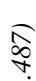

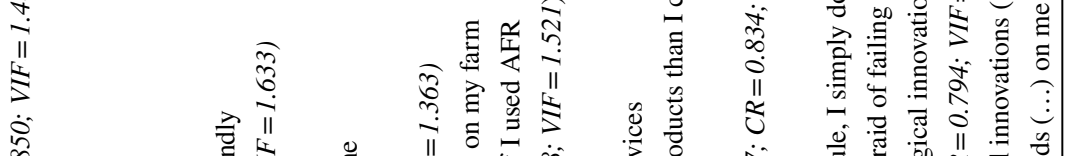

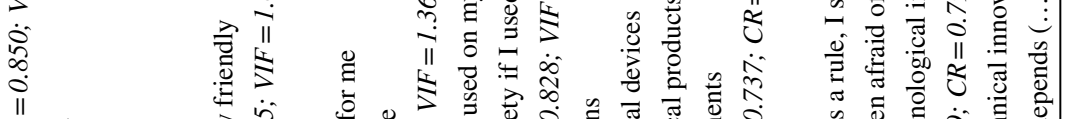




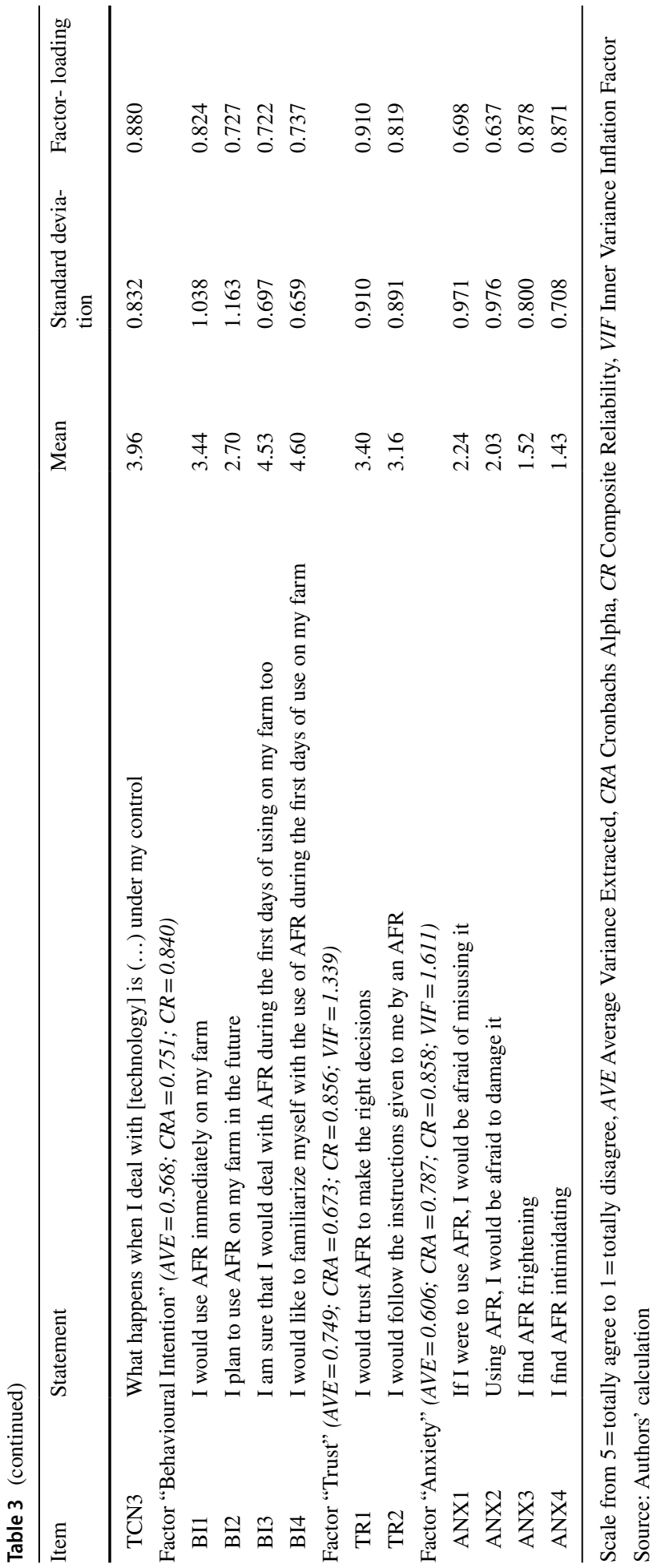


Table 4 Discriminant validity Fornell-Larcker criterion

\begin{tabular}{|c|c|c|c|c|c|c|c|c|c|}
\hline & BI & $\mathrm{EE}$ & PE & SI & ANX & TR & TCI & TCM & $\mathrm{TCN}$ \\
\hline BI & 0.754 & & & & & & & & \\
\hline $\mathrm{EE}$ & -0.433 & 0.804 & & & & & & & \\
\hline PE & 0.576 & -0.284 & 0.730 & & & & & & \\
\hline SI & 0.474 & -0.175 & 0.443 & 0.859 & & & & & \\
\hline ANX & -0.418 & 0.467 & -0.306 & -0.226 & 0.778 & & & & \\
\hline TR & 0.430 & -0.282 & 0.388 & 0.371 & -0.253 & 0.866 & & & \\
\hline TCI & 0.370 & -0.358 & 0.287 & 0.217 & -0.230 & 0.157 & 0.739 & & \\
\hline TCM & -0.251 & 0.444 & -0.088 & 0.011 & 0.382 & -0.061 & -0.342 & 0.747 & \\
\hline $\mathrm{TCN}$ & 0.173 & -0.182 & 0.157 & 0.105 & -0.205 & 0.122 & 0.284 & -0.151 & 0.753 \\
\hline
\end{tabular}

Source: Authors' calculations (highlighted: square roots of AVE values; not highlighted values: construct correlations)

Table 5 Discriminant validity HTMT criterion

\begin{tabular}{|c|c|c|c|c|c|c|c|c|c|}
\hline & BI & $\mathrm{EE}$ & PE & SI & ANX & TR & TCI & TCM & $\mathrm{TCN}$ \\
\hline \multicolumn{10}{|l|}{ BI } \\
\hline $\mathrm{EE}$ & 0.575 & & & & & & & & \\
\hline PE & 0.697 & 0.374 & & & & & & & \\
\hline SI & 0.636 & 0.255 & 0.603 & & & & & & \\
\hline ANX & 0.523 & 0.642 & 0.353 & 0.272 & & & & & \\
\hline TR & 0.576 & 0.393 & 0.506 & 0.535 & 0.311 & & & & \\
\hline TCI & 0.482 & 0.491 & 0.374 & 0.311 & 0.307 & 0.225 & & & \\
\hline TCM & 0.337 & 0.609 & 0.122 & 0.062 & 0.554 & 0.079 & 0.474 & & \\
\hline TCN & 0.214 & 0.262 & 0.227 & 0.148 & 0.244 & 0.176 & 0.430 & 0.206 & \\
\hline
\end{tabular}

Source: Authors' calculations

Table 6 Results multigroup analysis - moderating effect of age and work experience between the constructs and the behavioural intention to use AFR

\begin{tabular}{|c|c|c|c|c|c|c|}
\hline \multirow[t]{3}{*}{ Path } & \multicolumn{6}{|c|}{ Path coefficients } \\
\hline & \multicolumn{3}{|l|}{ Age } & \multicolumn{3}{|c|}{ Work experience } \\
\hline & $<41 \mathrm{y}$ & $>40 y$ & $\Delta$ & $<22 \mathrm{y}$ & $>21 y$ & $\Delta$ \\
\hline $\mathrm{EE} \rightarrow \mathrm{BI}$ & -0.158 & -0.125 & 0.033 & -0.150 & -0.111 & 0.039 \\
\hline $\mathrm{PE} \rightarrow \mathrm{BI}$ & 0.339 & 0.304 & 0.035 & 0.329 & 0.305 & 0.025 \\
\hline $\mathrm{SI} \rightarrow \mathrm{BI}$ & 0.202 & 0.199 & 0.003 & 0.226 & 0.199 & 0.027 \\
\hline $\mathrm{ANX} \rightarrow \mathrm{BI}$ & -0.099 & -0.146 & 0.048 & -0.091 & -0.151 & 0.059 \\
\hline $\mathrm{TR} \rightarrow \mathrm{BI}$ & 0.103 & 0.162 & 0.059 & 0.084 & 0.169 & 0.084 \\
\hline $\mathbf{T C I} \rightarrow \mathbf{B I}$ & 0.016 & 0.220 & 0.204* & 0.086 & 0.133 & 0.048 \\
\hline $\mathbf{T C M} \rightarrow \mathbf{B I}$ & -0.178 & 0.013 & $0.190 *$ & -0.115 & -0.047 & 0.068 \\
\hline $\mathrm{TCN} \rightarrow \mathrm{BI}$ & 0.011 & -0.037 & 0.047 & 0.017 & 0.020 & 0.003 \\
\hline
\end{tabular}

Source: Authors' calculations

Significance level: $* \mathrm{p} \leq 0.05$ 
Table 7 Results multigroup analysis - moderating effect of gender between the constructs and the behavioural intention to use AFR

\begin{tabular}{llll}
\hline Path & \multicolumn{2}{l}{ Path coefficients } & \\
\cline { 2 - 4 } & \multicolumn{2}{l}{ gender } & $\Delta$ \\
\cline { 2 - 4 } & \multicolumn{1}{l}{} & \multicolumn{1}{l}{} \\
\hline $\mathrm{EE} \rightarrow \mathrm{BI}$ & -0.130 & -0.032 & 0.098 \\
$\mathrm{PE} \rightarrow \mathrm{BI}$ & 0.305 & 0.580 & 0.275 \\
$\mathrm{SI} \rightarrow \mathrm{BI}$ & 0.215 & 0.132 & 0.083 \\
$\mathrm{ANX} \rightarrow \mathrm{BI}$ & -0.146 & 0.090 & 0.236 \\
$\mathrm{TR} \rightarrow \mathrm{BI}$ & 0.133 & 0.176 & 0.043 \\
$\mathrm{TCI} \rightarrow \mathrm{BI}$ & 0.121 & 0.142 & 0.021 \\
$\mathrm{TCM} \rightarrow \mathrm{BI}$ & -0.066 & -0.227 & 0.160 \\
$\mathrm{TCN} \rightarrow \mathrm{BI}$ & -0.028 & 0.109 & 0.137 \\
\hline
\end{tabular}

Source: Authors' calculations

Significance level: $* \mathrm{p} \leq 0.05$

Authors' Contributions Conceptualization: FRvonV, LT, HH; Methodology: FRvonV, HH; Formal analysis and investigation: FRvonV; Writing_original draft preparation: FRvonV; Writing — review and editing: LT, HH; Resources: FRvonV; Supervision: HH.

Funding Open Access funding enabled and organized by Projekt DEAL. None.

Data Aavailability The datasets generated during and/or analysed during the current study are available from the corresponding author on reasonable request.

Code Availability Not applicable.

\section{Declarations}

Conflict of interest All authors declare that they have no conflict of interest.

Open Access This article is licensed under a Creative Commons Attribution 4.0 International License, which permits use, sharing, adaptation, distribution and reproduction in any medium or format, as long as you give appropriate credit to the original author(s) and the source, provide a link to the Creative Commons licence, and indicate if changes were made. The images or other third party material in this article are included in the article's Creative Commons licence, unless indicated otherwise in a credit line to the material. If material is not included in the article's Creative Commons licence and your intended use is not permitted by statutory regulation or exceeds the permitted use, you will need to obtain permission directly from the copyright holder. To view a copy of this licence, visit http://creativecommons.org/licenses/by/4.0/.

\section{References}

Ambong, R. M. A., \& Paulino, M. A. (2020). Analyzing rice farmers' intention to adopt modern rice technologies using technology acceptance model (TAM). Asian Research Journal of Agriculture, 13(1), 21-30.

Amin, K., \& Li, J. (2014) Applying farmer technology acceptance model to understand farmer's behavior intention to use ICT based microfinance platform: A comparative analysis between Bangladesh and China. Paper presented at the WHICEB Proceedings of the Wuhan International Conference on e-Business at AIS Electronic Library (AISeL), Wuhan, People's Republic of China

Ajzen, I. (1991). The theory of planned behavior. Organizational Behavior and Human Decision Processes, 50(2), 179-211. https://doi.org/10.1016/0749-5978(91)90020-T 
Ajzen, I. (2005). Atitudes, Personality and Behavior. Open University Press.

Austin, E. J., Willock, J., Deary, I. J., Gibson, G. J., Dent, J. B., Edwards-Jones, G., et al. (1998). Empirical models of farmer behaviour using psychological, social and economic variables part I: Linear modelling. Agricultural Systems, 58(2), 203-224. https://doi.org/10.1016/S0308-521X(98)00066-3

Baron, R., \& Kenny, D. (1986). The moderator-mediator variable distinction in social psychological research: Conceptual, strategic, and statistical considerations. Journal of Personality and Social Psychology, 51(6), 1173-1182. https://doi.org/10.1037//0022-3514.51.6.1173

Basu, S., Omotubora, A., Beeson, M., \& Fox, C. (2020). Legal framework for small autonomous agricultural robots. AI \& Society, 35, 113-134. https://doi.org/10.1007/s00146-018-0846-4

Beier, G. (1999). Kontrollüberzeugungen im Umgang mit Technik (Control convictions in dealing with technology). Report Psychologie, 24(9), 684-693.

Bem, D. J., \& Allen, A. (1974). On predicting some of the people some of the time: The search for crosssituational consistencies in behavior. Psychological Review, 81(6), 506-520. https://doi.org/10.1037/ h0037130

Bortz, J., \& Döring, N. (2006). Forschungsmethoden und Evaluation für Human- und Sozialwissenschaftler (Research methods and evaluation for human and social scientists). Springer-Verlag.

Bozionelos, N. (1996). Prevalence of computer anxiety in British managers and professionals. Psychological Reports, 78(3), 995-1002. https://doi.org/10.2466/pr0.1996.78.3.995

Brauer, R. R. (2017). Akzeptanz kooperativer Roboter im industriellen Kontext (Acceptance of cooperative robots in an industrial context). Universitätsverlag Chemnitz.

Brehm, J. W. (1966). A theory of psychological reactance. Academic Press.

Chikoye, D. M., Gupta, N. K., \& Kandadi, K. R. (2018). Application of UTAT in understanding the adoption of technologies for reducing post harvest maize in Zambia. International Journal of Agriculture and Environmental Research, 4(3), 610-636.

Chin, W. (1998). The Partial Least Squares Approach to Structural Equation Modeling. $g$ (pp. 295-336). Marcoulides, Methodology for Business and Management Modern Methods for Business Research Mahwah USA: Lawrence Erlbaum Associates Publishers.

Cohen, J. (1988) Statistical power analysis for the behavioral sciences. Hillsdale, USA: L. Erlbaum Associates

D’Antoni, J. M., Mishra, A. K., \& Joo, H. (2012). Farmers' perception of precision technology: The case of autosteer adoption by cotton farmers. Computers and Electronics in Agriculture, 87, 121-128. https:// doi.org/10.1016/j.compag.2012.05.017

Davis, F. (1989). Perceived Usefulness, Perceived Ease of Use, and User Acceptance of Information Technology. MIS Quarterly, 13(3), 319-340. https://doi.org/10.2307/249008

Davison, A. C., \& Hinkley, D. V. (1997). Bootstrap Methods and their Application. Cambridge University Press.

Destatis (2019) Landwirtschaftliche Betriebe. Betriebsgrößenstruktur landwirtschaftlicher Betriebe nach Bundesländern (Agricultural enterprises. Size structure of agricultural enterprises by federal states). https://www.destatis.de/DE/Themen/Branchen-Unternehmen/Landwirtschaft-Forstwirtschaft-Fisch erei/Landwirtschaftliche-Betriebe/Tabellen/betriebsgroessenstruktur-landwirtschaftliche-betriebe. html. Accessed 2 January 2020

Devitt, S. K. (2018). Cognitive factors that affect the adoption of autonomous agriculture. Farm Policy Journal, 15(2), 49-60.

Diamantopoulos, A. (2011). Incorporating formative measures into covariance-based structural equation models. MIS Quarterly, 35(2), 335-358. https://doi.org/10.2307/23044046

Dixon, S., \& Wickens, C. (2006). Automation reliability in unmanned aerial vehicle control: A reliancecompliance model of automation dependence in high workload. Human Factors, 48(3), 474-486. https://doi.org/10.1518/001872006778606822

Dixon, S., Wickens, C., \& McCarley, J. (2007). On the independence of compliance and reliance: are automation false alarms worse than misses? Human Factors, 49(4), 564-572. https://doi.org/10. 1518/001872007X215656

Efron, B., \& Tibshirani, R. (1986). bootstrap methods for standard errors, confidence intervals, and other measures of statistical accuracy. Statistical Science, 1(1), 54-75.

Eurobarometer (2012). Public Attitudes towards Robots. Special Eurobarometer 382. https://ec.europa. eu/commfrontoffice/publicopinion/index.cfm/Survey/getSurveyDetail/instruments/SPECIAL/ surveyKy/1044/p/3. Accessed 10 November 2019.

Eurostat (2019). Labour force main indicators. https://appsso.eurostat.ec.europa.eu/nui/submitView TableAction.do. Accessed 29 August 2019.

Far, S. T., \& Rezaei-Moghaddam, K. (2015). Determinants of Iranian agricultural consultants' intentions toward precision agriculture: integrating innovativeness to the technology acceptance model. 
Journal of the Saudi Society of Agricultural Sciences, 16(3), 280-286. https://doi.org/10.1016/j. jssas.2015.09.003

Ferretti, M. P., \& Pavone, V. (2009). What do civil society organisations expect from participation in science? Lessons from Germany and Spain on the issue of GMOs. Science \& Public Policy - SCI PUBLIC POLICY, 36(4), 287-299. https://doi.org/10.3152/030234209X436527

Fornell, C., \& Larcker, D. F. (1981). Evaluating structural equation models with unobservable variables and measurement error. Journal of Marketing Research, 18(1), 39-50. https://doi.org/10.2307/ 3151312

Foster, A. D., \& Rosenzweig, M. R. (1995). Learning by doing and learning from others: Human capital and technical change in agriculture. Journal of Political Economy, 103(6), 1176-1209. https://doi. org/10.1086/601447

Friedrich, T., Derpsch, R., \& Kassam, A. (2012). Overview of the global spread of conservation agriculture. Field Actions Science Report, 6(1), 1-7. https://doi.org/10.1080/00207233.2018.1494927

Gallimore, D., Lyons, J. B., Vo, T., Mahoney, S., \& Wynne, K. T. (2019). Trusting robocop: genderbased effects on trust of an autonomous robot. Frontiers in Psychology. https://doi.org/10.3389/ fpsyg.2019.00482

Gefen, D., Karahanna, E., \& Straub, D. (2003). Inexperience and experienced with online stores: the importance of TAM and Trust. IEEE Transactions on Engineering Management, 50(3), 307-321.

German Farmers' Association (2019). Situationsbericht 2019/20 (Situation report). Trends und Fakten zur Landwirtschaft (Trends and facts about agriculture). Berlin: DBV.

Gerybadze, A. (2015). Instrumente der Innovationspolitik. Auf dem Weg zu einer neuen Industriepolitik? (Instruments of innovation policy. Towards a new industrial policy?). WSI-Mitteilungen, 68, 516-525. https://doi.org/10.5771/0342-300X-2015-7-516

Ghazali, A. S., Ham, J., Barakova, E., \& Markopoulos, P. (2018). Effects of robot facial characteristics and gender in persuasive human-robot interaction. Frontiers in Robotics and AI, 5, 1-16. https:// doi.org/10.3389/frobt.2018.00073

Gloy, B. A., \& Akridge, J. (2000). Computer and internet adoption on large U.S. farms. The International Food and Agribusiness Management Review, 3(3), 323-338. https://doi.org/10.1016/S10967508(01)00051-9

Götz, O., Liehr-Gobbers, K., \& Krafft, M. (2010). Evaluation of Structural equation models using the partial least squares PLS Approach In V Esposito Vinzi, WW Chin, J Henseler, H Wang, Handbook of Partial Least Squares: Concepts (pp. 691-711). Methods and Applications Heidelberg Germany: Springer, Berlin Heidelberg.

Hair, J. F., Hult, G., Ringle, C., \& Sarstedt, M. (2016). A Primer on Partial Least Squares Structural Equation Modeling (2nd ed.). Sage Publications.

Hair, J. F., Ringle, C., \& Sarstedt, M. (2011). PLS-sem: Indeed a silver bullet. The Journal of Marketing Theory and Practice, 19, 139-151. https://doi.org/10.2753/MTP1069-6679190202

Heerink, M., Krose, B., Evers, V., \& Wielinga, B. (2010). Assessing acceptance of assistive social agent technology by older adults: the almere model. International Journal of Social Robotics, 2(4), 361375. https://doi.org/10.1007/s12369-010-0068-5

Henseler, J (2005) Einführung in die PLS Pfadmodellierung. WiSt Wirtschaftswissenschaftliches Studium 34(2): 70-75 Doi: https://doi.org/10.15358/0340-1650-2005-2-70

Henseler, J., \& Chin, W. W. (2010). A comparison of approaches for the analysis of interaction effects between latent variables using partial least squares path modeling. Structural Equation Modeling: A Multidisciplinary Journal, 17(1), 82-109. https://doi.org/10.1080/10705510903439003

Henseler, J., Ringle, C., \& Sarstedt, M. (2015). A new criterion for assessing discriminant validity in variance-based structural equation modeling. Journal of the Academy of Marketing Science, 43(1), 115135. https://doi.org/10.1007/s11747-014-0403-8

Henseler, J., Ringle Christian, M., \& Sinkovics Rudolf, R. (2009) The use of partial least squares path modeling in international marketing. In R. S. Rudolf, \& N. G. Pervez (Eds.), New Challenges to International Marketing (Vol. 20, pp. 277-319, Advances in International Marketing). Bingley, UK: Emerald Group Publishing Limited.

Hertzberg, J. (2014). Autonome Systeme in der Landwirtschaft (Autonomous Systems in Agriculture). KTBL.

Hiebert, L. D. (1974). Risk, learning, and the adoption of fertilizer responsive seed varieties. American Journal of Agricultural Economics, 56(4), 764-768. https://doi.org/10.2307/1239305

Hoag, D. L., Ascough, J. C., \& Frasier, W. M. (1999). Farm computer adoption in the great plains. Journal of Agricultural and Applied Economics, 31(1), 57-67. https://doi.org/10.1017/S0081305200028776

Hornburg, C., \& Giering, A. (1996). Konzeptualisierung und Operationalisierung komplexer Konstrukte Ein Leitfaden für die Marketingforschung (Conceptualization and operationalization of complex 
constructs A guide for marketing research). Marketing ZFP, 18(1), 5-24. https://doi.org/10.15358/ 0344-1369-1996-1-5

Hulland, J. (1999). Use of partial least squares (PLS) in strategic management research: A review of four recent studies. Strategic Management Journal, 20(2), 195-204. https://doi.org/10.1002/(SICI)10970266(199902)20:2\%3c195::AID-SMJ13\%3e3.0.CO;2-7

Isgin, T., Bilgic, A., Forster, D. L., \& Batte, M. T. (2008). Using count data models to determine the factors affecting farmers' quantity decisions of precision farming technology adoption. Computers and Electronics in Agriculture, 62(2), 231-242. https://doi.org/10.1016/j.compag.2008.01.004

Jacobs, B., Hartog, J., \& Vijverberg, W. (2009). Self-selection bias in estimated wage premiums for earnings risk. Empirical Economics, 37(2), 271-286. https://doi.org/10.1007/s00181-008-0231-0

Kester, C., Griepentrog, H. W., Hörner, R., \& Tuncer, Z. (2013) A survey of future farm automation - a descriptive analysis of survey responses. In J. V. Stafford (Ed.), Precision Agriculture'13. Wageningen, Netherlands: Wageningen Academic Publishers, doi: https://doi.org/10.3920/978-90-8686-7783_97 pp. 785-792

King, A. (2017). Technology: the future of agriculture. Nature, 544(7651), 21-23. https://doi.org/10.1038/ 544 S21a

Krampen, G. (1991). Fragebogen zu Kompetenz- und Kontrollüberzeugungen: (FKK); Handanweisung (Questionnaire on competence and control convictions: (QCC); manual instruction). Hogrefe Verlag.

Krampen, G., Viebig, J., \& Walter, W. (1982). Entwicklung einer Skala zur Erfassung dreier Aspekte von sozialem Vertrauen (Development of a scale to measure three aspects of social trust). Diagnostica, 28(3), 242-247.

Kuczera, C. (2006). Der Einfluss des sozialen Umfeldes auf betriebliche Entscheidungen von Landwirten. Margraf Publishers.

Kulviwat, S., Bruner, G. C., II., Kumar, A., Nasco, S. A., \& Clark, T. (2007). Toward a unified theory of consumer acceptance technology. Psychology \& Marketing, 24(12), 1059-1084. https://doi.org/10. 1002/mar.20196

Kutter, T., Tiemann, S., Siebert, R., \& Fountas, S. (2011). The role of communication and co-operation in the adoption of precision farming. Precision Agriculture, 12, 2-17. https://doi.org/10.1007/ s11119-009-9150-0

Larson, J., Roberts, R., English, B., Larkin, S., Marra, M., Martin, S., et al. (2008). Factors affecting farmer adoption of remotely sensed imagery for precision management in cotton production. Precision Agriculture, 9(4), 195-208. https://doi.org/10.1007/s11119-008-9065-1

Levy, J. A. (1988). Intersections of gender and aging. The Sociological Quarterly, 29(4), 479-486.

Lohmöller, J.-B. (1988). The PLS program system: latent variables path analysis with partial least squares estimation. Multivariate Behavioral Research, 23(1), 125-127. https://doi.org/10.1207/s15327906m br2301_7

Lowenberg-DeBoer, J., Huang, I. Y., Grigoriadis, V., \& Blackmore, S. (2020). Economics of robots and automation in field crop production. Precision Agriculture, 21(2), 278-299. https://doi.org/10.1007/ s11119-019-09667-5

Lutz, K. J. (2017). Digitalisierung der Landwirtschaft: Revolution mit evolutionärem Charakter (Digitization of agriculture: Revolution with evolutionary character). In A. Hildebrandt, \& W. Landhäußer (Eds.), CSR und Digitalisierung. Der digitale Wandel als Chance und Herausforderung für Wirtschaft und Gesellschaft (CSR and digitization. Digital change as an opportunity and challenge for business and society) (pp. 429-442). Berlin, Germany: Springer Gabler

MacMillan, K., Money, K., Downing, S., \& Hillenbrand, C. (2005). Reputation in relationships: measuring experiences Emotions and Behaviors. Corporate Reputation Review, 8(3), 214-232. https:// doi.org/10.1057/palgrave.crr.1540251

McAllister, D. J. (1995). Affect- and cognition-based trust as foundations for interpersonal cooperation in organizations. The Academy of Management Journal, 38(1), 24-59. https://doi.org/10.2307/ 256727

Meyer, J. (2001). Effects of warning validity and proximity on responses to warnings. Human Factors, 43(4), 563-572. https://doi.org/10.1518/001872001775870395

Meyer, J. (2004). Conceptual Issues in the study of dynamic hazard warnings. Human Factors, 46(2), 196-204. https://doi.org/10.1518/hfes.46.2.196.37335

Minßen, T.-F., Urso, L.-M., Gaus, C.-C., \& Frerichs, L. (2015). Mit autonomen Landmaschinen zu neuen Pflanzenbausystemen (With autonomous agricultural machinery to new crop production systems). Atzoffhighway, 8(3), 6-11. https://doi.org/10.1007/s35746-015-0028-y

Minton, H. L., \& Schneider, F. W. (1980). Differential psychology. Waveland Press. 
Morris, M. G., \& Venkatesh, V. (2000). Age differences in technology adoption decisions: implications for a changing workforce. Personnel Psychology, 53(2), 375-403. https://doi.org/10.1111/j.17446570.2000.tb00206.x

Mußhoff, O., Hirschauer, N., \& Wassmuss, H. (2009) The Role of Bounded Rationality in Farm Financing Decisions - First Empirical Evidence -. Paper presented at the International Association of Agricultural Economists (IAAE) 2009 Conference, Beijing, China, 2009

Neyer, F. J., Felber, J., \& Gebhardt, C. (2012). Entwicklung und Validierung einer Kurzskala zur Erfassung von Technikbereitschaft (Development and validation of a short scale to measure technology readiness). Diagnostica, 58(2), 87-99. https://doi.org/10.1026/0012-1924/a000067

Nomura, T., Suzuki, T., Kanda, T., \& Kato, K. (2006). Measurement of Anxiety toward Robots

Orcutt, G. H., Watts, H. W., \& Edwards, J. B. (1968). Data aggregation and information loss. The American Economic Review, 58(4), 773-787.

Pickel, P. (2019). RoundTable: Agricultural robotics storms global market. Presentation on the International Forum of Agricultural Robotics (FIRA). Toulouse: International Forum of Agricultural Robotics (FIRA).

Pierpaoli, E., Carli, G., Pignatti, E., \& Canavari, M. (2013). Drivers of precision agriculture technologies adoption: a literature review. Procedia Technology, 8, 61-69. https://doi.org/10.1016/j.protcy. 2013.11.010

Plude, D., \& Hoyer, W. (1985). Attention and Performance: Identifying and Localizing Age Deficits. In N. Charness (Ed.), Aging and Human Performance (pp. 47-99). John Wiley and Sons.

Redhead, F., Snow, S., Vyas, D., Bawden, O., Russell, R., Perez, T., et al. (2015) Bringing the Farmer Perspective to Agricultural Robots. Paper presented at the Proceedings of the 33rd Annual ACM Conference Extended Abstracts on Human Factors in Computing Systems, Seoul, Republic of Korea

Renner, B., Spivak, Y., Kwon, S., \& Schwarzer, R. (2007). Does age make a difference? predicting physical activity of South Koreans. Psychology and Aging, 22(3), 482-493. https://doi.org/10.1037/ 0882-7974.22.3.482

Retter, C., Stahr, K., \& Boland, H. (2002). Zur Rolle von Landwirten in dörflichen Kommunikationsnetzwerken (The role of farmers in rural communication networks). Berichte Über Landwirtschaft, 80(3), 446-467.

Rhodes, S. R. (1983). Age-related differences in work attitudes and behavior: A review and conceptual analysis. Psychological Bulletin, 93(2), 328-367. https://doi.org/10.1037/0033-2909.93.2.328

Rial-Lovera, K (2018) Agricultural Robots: Drivers, Barriers and Opportunities for Adoption. In 14th International Conference on Precision Agriculture, 24 - 27 June 2018: The International Society of Precision Agriculture.

Rübcke von Veltheim, F., Theuvsen, L., \& Heise, H. (2019). Akzeptanz autonomer Feldroboter im Ackerbaueinsatz: Status quo und Forschungsbedarf (Acceptance of autonomous field robots in arable farming: Status quo and research needs). Berichte Über Landwirtschaft, 97(3), 1-19. https://doi. org/10.12767/buel.v97i3.248

Sarstedt, M., Henseler, J., \& Ringle Christian, M. (2011). Multigroup Analysis in Partial Least Squares (PLS) Path Modeling: Alternative Methods and Empirical Results. In S. Marko, S. Manfred, \& R. T. Charles (Eds.), Measurement and Research Methods in International Marketing, Advances in International Marketing). Bingley, UK: Emerald Group Publishing Limited Vol. 22, pp. 195-218

Schukat, S., Kuhlmann, A., \& Heise, H. (2019). Fattening Pig farmers' intention to participate in animal welfare programs. Animals, 9(12), 1042. https://doi.org/10.3390/ani9121042

Shockley, J. M., Dillon, C. R., \& Shearer, S. A. (2019). An economic feasibility assessment of autonomous field machinery in grain crop production. Precision Agriculture, 20(5), 1068-1085. https://doi.org/10. 1007/s11119-019-09638-w

Simon, H. A. (1956). Rational choice and the structure of the environment. Psychological Review, 63(2), 129-138. https://doi.org/10.1037/h0042769

Solano, C., León, H., Pérez, E., \& Herrero, M. (2003). The role of personal information sources on the decision-making process of Costa Rican dairy farmers. Agricultural Systems, 76(1), 3-18. https://doi. org/10.1016/S0308-521X(02)00074-4

Tamirat, T., Pedersen, S. M., \& Lind, K. (2017). Farm and operator characteristics affecting adoption of precision agriculture in Denmark and Germany. Acta Agriculturae Scandinavica, Section B - Soil \& Plant Science, 68(4), 349-357. https://doi.org/10.1080/09064710.2017.1402949

Tey, Y. S., \& Brindal, M. (2012). Factors influencing the adoption of precision agricultural technologies: A review for policy implications. Precision Agriculture, 13(6), 713-730. https://doi.org/10.1007/ s11119-012-9273-6 
Turja, T., Aaltonen, I., Taipale, S., \& Oksanen, A. (2019). Robot acceptance model for care (RAM-care): A principled approach to the intention to use care robots. Information \& Management, 57(5), 10322. https://doi.org/10.1016/j.im.2019.103220

Venkatesh, V., \& Davis, F. D. (2000). A theoretical extension of the technology acceptance model: four longitudinal field studies. Management Science, 46(2), 186-204. https://doi.org/10.1287/mnsc.46.2. 186.11926

Venkatesh, V., \& Morris, M. G. (2000). Why Don't men ever stop to ask for directions? Gender, social influence, and their role in technology acceptance and usage behavior. MIS Quarterly, 24(1), 115-139. https://doi.org/10.2307/3250981

Venkatesh, V., Morris, M. G., Davis, G. B., \& Davis, F. D. (2003). User acceptance of information technology: toward a unified view. MIS Quarterly, 27(3), 425-478. https://doi.org/10.2307/30036540

Venkatesh, V., Thong, J. Y. L., Chan, F. K. Y., Hu, P. J. H., \& Brown, S. A. (2011). Extending the two-stage information systems continuance model - Incorporating UTAUT predictors and the role of context. Information Systems Journal, 21(6), 527-555. https://doi.org/10.1111/j.1365-2575.2011.00373.x

Venkatesh, V., Thong, J. Y. L., \& Xu, X. (2012). Consumer acceptance and use of information technology: extending the unified theory of acceptance and use of technology. MIS Quarterly, 36(1), 157-178. https://doi.org/10.2307/41410412

Voss, J., Schaper, C., Spiller, A., \& Theuvsen, L. (2008). Innovationsverhalten in der deutschen Landwirtschaft - Empirische Ergebnisse am Beispiel der Biogasproduktion. Paper presented at the 48th Annual Conference, September 24-26, 2008.

Weidner, R., Redlich, T., \& Wulfsberg, J. P. (2015). Technische Unterstützungssysteme (Technical support systems). Wiesbaden, Germany: Springer Vieweg.

Zander, K., Isermeyer, F., Bürgelt, D., Christoph-Schulz, I. B., Salamon, P., \& Weible, D. (2013). Erwartungen der Gesellschaft an die Landwirtschaft (Society`s expectations of agriculture) Münster, Germany: Stiftung Westfälische Landwirtschaft

Zimmermann, M. (2003). Das Kaufverhalten von Landwirten im Bereich landwirtschaftlicher Investitionsgüter und die Auswirkung auf den Marketing-Mix landtechnischer Unternehmen (The purchasing behavior of farmers in the area of agricultural capital goods and the impact on the marketing mix of agricultural technology companies) (1st Ed.). Cuvillier Verlag

Zühlsdorf, A., Spiller, A., Gauly, S., \& Kühl, S. (2016) Wie wichtig ist Verbrauchern das Thema Tierschutz? Präferenzen, Verantwortlichkeiten, Handlungskompetenzen und Politikoptionen (How important is the topic of animal welfare to consumers? Preferences, responsibilities, competencies and policy options). Berlin, Germany: Zühlsdorf + Partner GbR

Publisher's Note Springer Nature remains neutral with regard to jurisdictional claims in published maps and institutional affiliations. 